\title{
Didactical Design of Circle Equation and Tangent of Circle Analytic Geometry Learning
}

\author{
Nanang Diana ${ }^{1}$, Didi Suryadi ${ }^{2}$, Jarnawi Afgani Dahlan ${ }^{3}$ \\ \{nanangdiana_mathematics@upi.edu ${ }^{1}$ \}
}

\begin{abstract}
Departemen Pendidikan Matematika, Universitas Pendidikan Indonesia, Jl. Dr. Setiabudi No. 229, Bandung 40154, Indonesia ${ }^{1,2,3}$, STKIP Taman Siswa Bima, Jl. Pendidikan No.01 Palibelo-Bima ${ }^{1}$
\end{abstract}

\begin{abstract}
This study aims to formulate an alternative learning design related to the concept of circle equations and tangents to analytic geometry learning through student learning obstacles. This is descriptive qualitative didactic design research (DDR) by identifying the learning obstacle of students obtained equations of circular equations and tangents of circles, then compiling pedagogical didactic anticipations through identified learning obstacles. This research subject is the sixth-semester students of analytic geometry courses. Data collection was carried out using documentation, interview, test and questionnaire techniques. The results showed an alternative didactic design that could be used in the learning equation of circles and tangents of circles and were able to facilitate students as a source of support for learning activities.
\end{abstract}

Keywords: Didactical Design, Circle Equation and Tangent of Circle, Learning Obstacle

\section{Introduction}

Education is a conscious and planned effort to create an atmosphere of learning process for students to actively develop their potential to have spiritual strength, self-control, personality, intelligence, noble character, and the skills needed by the community. Education can also be interpreted as a systematic effort to achieve a standard of living or for better progress. Education can develop character through a variety of activities, such as instilling values, developing character, religious values, learning and training moral values, and so on. Mathematical learning is basically related to three things, namely teacher, students, and material [1]. According to Kansanen, there are two basic aspects of mathematics learning, namely the relationship among students and materials and teachers [2]. The relationship between teacher and student is called pedagogical relation (Relationship Pedagogical / HP) while the relationship between students with the material is called didactical reflection (HD), which is usually presented in a didactic triangle. Furthermore, [2] states that the teacher's relationship with the material cannot be ignored.

According to [2], HD and HP cannot be viewed partially but can occur simultaneously. In this case, the teacher can design a didactic situation and make predictions of student responses and anticipation until a new situation is created. Thus, in the didactic triangle, it is necessary to add an anticipatory relationship between the teacher and students, called the ADP (Anticipation of Didactic Pedagogical).

The didactic triangle teacher's role is to create a didactic situation so that the learning process occurs within. This indicates that the teacher must really master teaching material, 
knowledge of students, and create didactic situations to optimize learning also known as the didactic relation. A didactic and pedagogical situation is a very complex thing, so the teacher must have the ability to look at it comprehensively, identifying and analyzing the important things that happened, and taking appropriate actions to make the learning optimal. This ability is furthermore referred to as methapeda didactic.

Generally, students who usually listen passively to become active by starting to do exercises taken. The meaninglessness of the mathematics learning process, in addition to the lack of student involvement in learning and thinking, also arises because in the learning process, students understand mathematical concepts partially (parts), are not integrated between one concept with another concept. In fact, mathematics is a science that is built from a variety of structured topics so that the learning process is done in stages (gradually) that start from easy concepts to more difficult concepts. in learning Mathematics of Geometry, especially in the concept of equations of circles and tangents to circles. The interrelationship between concepts in geometry is very close, making several things students need to know before they learn the concepts of equations and tangents of circles including students must first understand the concept of circles and their properties, concepts of lines, Cartesians coordinates and theorem Pythagoras. If the initial concepts that are the prerequisites of a Geometry concept are not understood yet, it is certain that students are not able to understand the concept. In studying Geometry related to the concepts of equations and Tangents of circles, the facts on the ground show that the level of mastery of students over this material is still lacking.

In developing a concept of learning the equation of a circle and tangent circles that are not textual anymore, the effort that needs to be done by a teacher is the need to develop a learning design (Didactic Design) as a first step before learning. Didactic is a design of teaching materials that can educate and teach students compiled based on research on learning obstacles (learning obstacles) in this case is an epistemological obstacle of material in mathematics learning. According to Duroux [2] argues that the Epistemological obstacle is essentially a person's knowledge which is only limited to a particular context. If the student is confronted with a different context, the knowledge possessed cannot be used or difficulty using it. [2] argued that learning obstacles, especially epistemological ones, is one aspect that teachers need to consider in developing didactic and pedagogical anticipation. With a didactic design oriented to research on the obstacles experienced by students on a certain concept in mathematics, students are expected to no longer encounter significant obstacles during the process of understanding the concept. So that the goal of learning mathematics as an effort to achieve the goals of national education can be realized well with this didactic design students can better and apply the concepts learned.

In this study, the concepts and context of the circle and tangent circles and how didactic designs on the concept of the equation of circles and tangents to be able to overcome learning obstacle in accordance with the characteristics of sixth-semester students and the implementation of didactic designs, especially in terms of student responses which appears in analytic geometry learning.

\section{Method}

Method of the Research is a didactic design focused on the equations of circles and tangents of circles in analytic Geometry courses. This type of research is a qualitative descriptive study with data collected in the form of words, pictures, and not numbers. This study intended to 
understand the phenomena about what is experienced by the research subjects, for example, Behavior, Perception, Motivation, Action, etc. holistically [3]. The formal steps in didactic design research are; 1) Didactic situation analysis before learning in the form of a hypothetical didactic design including ADP, 2) Methapedadedactic, 3) retrospective in the form of an analysis linking the results of a hypothetical didactic situation analysis with the results of a didactic method design [4]. Before doing the initial didactic design arrangement of the circle equation and the tangent of the circle, the first step to do is to test the instrument to get the learning obstacle to students who have learned the sub-material. The next step is to analyze the learning trajectory, including analyzing the source book as a guide for students and teachers and analyzing the learning video. Based on the obstacle learning and learning trajectory obtained can be a reference to compile an initial didactic design that can overcome students' difficulties.

The subjects in this study were divided into two parts, namely the subject to identify initial learning obstacles and the subject for didactic design implementation and the identification of the final learning obstacle. Subjects in the identification of initial learning obstacles were students who had gotten circle equations and tangent material totaling 16 students in the sixth semester, while in the implementation of didactic design and identification of final learning obstacle were students in three semesters in odd semester who were able to take analytic geometry courses.

The instruments used were test and non-test. Test was used to identify the initial learning obstacle and the identification of the late learning obstacle which aimed to find out the picture of the learning obstacle as a result of the didactic design that had been implemented. Test consists of five essay questions with different characteristics from each other, including the ability to understand concepts related to the concept of equations of circles and tangents of circles and prerequisite material, variations in information, connections, and problem solving. As for the non-test instruments used interviews, observation, questionnaires, and documentation. Analysis of the data in this study was to use the Miles and Huberman model including Data Reduction, Display, and Conclusion Drawing.

\section{Results and Discussion}

This research didactic design on the material of equations of circles and tangents in analytic geometry courses based on learning obstacle in the form of didactical and epistemological obstacle, then the findings of learning obstacle were analyzed through didactic situation analysis which was carried out before learning, methangedicalactic analysis conducted when learning and retrospective analysis conducted after learning.

Learning obstacles faced by students in learning material tangent to the circle that students have difficulty in solving problems related to the tangent circle. From the interview results found that students experienced problems in understanding the concept of equations and tangents of a circle, due to the lack of references. In this case, students do not understand the correct concept of equations and tangents. students still have difficulty in choosing and using information available to solve problems related to the concept of equations of circles and tangents of circles such as the lack of student knowledge and the difficulty of using the Pythagorean theorem in calculating the length of the tangents of the circle because the students understood in full that the radius of a circle is always perpendicular to the tangent of a circle.

Students must be demanded to actively construct the concept of equations and tangents of circles, students are expected to be able to understand the meaning and the properties of circles 
so that the concepts they get are not easily forgotten. To support the construction of concepts, problem solving is done in groups because it is based on [5] which states that social interaction or conversation with an expert will result in students being able to develop concepts more systematically, logically, and rationally.

The didactic situation analysis stage is the initial stage in the form of a didactic design hypothesis including a pedagogical didactic analysis (ADP) which begins with the repersonalization and re-contextualization of the material on equations and tangents of circles from various sources of textbooks. Learning of equations and tangents of circles is a study in the field of analytic geometry that is in the area of the Cartesian which is represented as an equation in the form of algebraic form (see Figure 1).

\section{Circle Definition:}

A circle is a place where points (on a flat plane) are the same distance from a certain point. Furthermore, certain points are called the center of the circle and the same distance is called the radius of the circle.

\section{Circle Equation:}

- $\quad$ Center on $(0,0)$ and radius $r: x^{2}+y^{2}=r^{2}$

- Center on $\mathrm{P}(\mathrm{a}, \mathrm{b})$ and radius $r:(x-a)^{2}+(y-b)^{2}=r^{2}$

- General form : $x^{2}+y^{2}+A x+B y+C=0$

Tangent Circle Definition:

Tangent circle is a intersecting or tangent to a circle only called a point. Furthermore, the point is called the point of tangency. The tangent of a circle tangent can be determined if the tangent gradient is known, or the tangent point is known, or it can also be determined if the line passes through a point outside the circle.

\section{Tangent to the circle}

- If tangent gradient is known: $y=m x+r \sqrt{1+m^{2}}$ and $y=m x-r \sqrt{1+m^{2}}$

- Through the points on the circle $x^{2}+y^{2}=r^{2}$ in point $\left(x_{1}, y_{1}\right)$ is $x^{2}+y^{2}=r^{2}$

- $\quad$ Through the point outside the circle $(x-a)^{2}+(y-b)^{2}=r^{2}$

Fig. 1. Material Equations for circles and tangents to circles.

Learning trajectory equation of circle and tangent circle contains a general equation of a circle whose center and radius are known in the form of equation $(\boldsymbol{x}-\boldsymbol{a})^{2}+(\boldsymbol{y}-\boldsymbol{b})^{\mathbf{2}}=\boldsymbol{r}^{\mathbf{2}}$ which can be changed into other forms is $\boldsymbol{x}^{2}+\boldsymbol{y}^{2}+\boldsymbol{A x}+\boldsymbol{B} \boldsymbol{y}+\boldsymbol{C}=\mathbf{0}$ while the tangents of the circle passing through the circle on the equation with the tangents of the circle $\left(x^{2}+y^{2}\right)=$ $\boldsymbol{r}^{2}$ in point $\left(\boldsymbol{x}_{1}, \boldsymbol{y}_{1}\right)$ is $\boldsymbol{x}_{1} \boldsymbol{x}+\boldsymbol{y}_{1} \boldsymbol{y}=\boldsymbol{r}^{2}$. From learning trajectory, it will be developed into a Didactic Design Hypothesis which is a re-contextualization activity based on student obstacle learning and from various previous studies.

Based on the theory of didactic situations proposed by [6], revealed that there is a very important relationship between students and the learning environment Didactic situation theory consists of action, formulation, validation, and institutionalization. Action is a reciprocal relationship between students and learning situations. Starting from a problem that causes students to make hypotheses, then students determine the strategy which is then proven true. Formulation is an opportunity given to students to create models implicitly created by themselves. Furthermore, the validation stage, which is a model obtained from the action and 
formulation steps, can be accepted or rejected by other students. All students of learning have the same position so that they can discuss their strategy, the alleged strategy or way of settlement agreed by all of them will be the right choice. The last stage of institutionalization is the application of theory in daily life. This situation gives value to the truth of the knowledge learned in class. This process is linked to concepts, symbols and knowledge that might be used at different times and for different purposes.

Based on the didactic theory of matter the circle equation in the action activities of the circle equation is formed from the concept of distance between and the center of the circle, where students must understand the elements in the circle such as understanding the concept of radius, center of circle, juring and diameter, besides that students must be able to understand the initial concept implanted that is able to understand the circle and calculate the distance between several points both side of the circle. The action process begins with questions and answers to students on how to make triangles aimed to determine the point to be presented. The expected response is to be able to draw line segments with known lengths that are centered at a certain point. Circular formulation activities centered on $\left(\frac{1}{2}, 2\right)$ and fingers 3 unit so the circle equation is $\left(x-\frac{1}{2}\right)^{2}+(y+2)^{2}=9$ so the general shape is a circle is $x^{2}+y^{2}-x+4 y-\frac{19}{4}=0$. This equation is proved by the concept of distance between two points centered on the point $\left(\frac{1}{2}, 2\right)$ and fingers 3 unit. The expected response to students is students are able to understand the questions given by answering using a distance of two points, but students are still confused applying it.

When validating student understanding in determining the central point and radius, students complete problem solving by simplifying the form of the equation so that it can be seen whether students are able to understand the general concepts of circle equations and their applications. Here is the shape of the circle equation which is centered at $(a, b)$ the fingers $r$

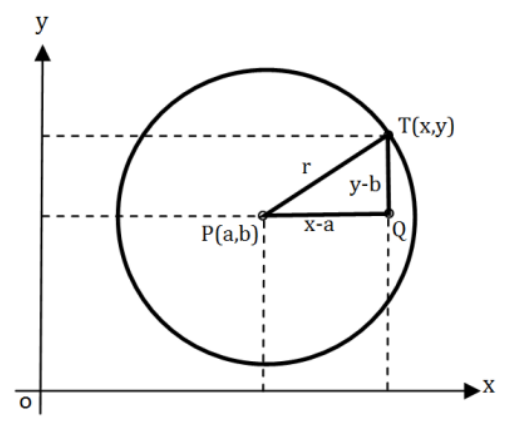

Fig. 2. The shape of a circle equation centered on fingers $(a, b)$ the fingers $r$

In Figure 2 a circle with a center appears $\mathrm{P}(\mathrm{a}, \mathrm{b})$ and the radius of $r$ unit. and To determine this equation, take any point on the circle, for example, the radius of $\mathrm{r}$ unit $\mathrm{T}(x, y)$ On a right triangle PQT obtained the distance of the points $\mathrm{T}$ and $\mathrm{P}$ is $\sqrt{(x-a)^{2}+(y-b)^{2}}$. Where as the distances of the $\mathrm{T}$ and $\mathrm{P}$ points are the radius of the circle, $r$, so that the relationship that:

$$
\sqrt{(x-a)^{2}+(y-b)^{2}}=r
$$




$$
(x-a)^{2}+(y-b)^{2}=r^{2}
$$

because $\mathrm{T}(x, y)$ is any point on the circle, then each point on the circle fills the circle. this means that the circle equation centered at point $\mathrm{P}(\mathrm{a}, \mathrm{b})$ with the unit radius is

$$
(x-a)^{2}+(y-b)^{2}=r^{2}
$$

Didactic design on the concept of equations of tangents of circles with certain gradients $(m)$ with the aim of students being able to represent images of tangents of circles on cartesian coordinates whose gradient is known to be an algebraic form. Suppose that the tangent of a circle flanks an angle $\mathbf{6 0}^{\circ}$ with axis $\boldsymbol{x}$ positive direction with $x^{2}+y^{2}-4 x-6 y-3=0$. In completing this problem the ability of students to manipulate algebraic forms is needed in accordance with the theory of didactic situations. The nature of the action in solving this problem is to understand the position of the line that is offensive to the circle and draw the tangent equation of a certain gradient (see Figure 3).

$$
\begin{aligned}
& \text { Problem solving: } \begin{array}{c}
x^{2}+y^{2}-4 x-6 y-3=0 \\
x^{2}-4 x+4+y^{2}-4 x-6 y+9=16 \\
(x-2)^{2}+(y-3)^{2}=16
\end{array} \\
& \text { Tangent line equation with gradient } m=\sqrt{3} \text { is } \\
& y-3=\sqrt{3}(x-2)+4 \sqrt{1+3} \text { and } y-3=\sqrt{3}(x-2)-4 \sqrt{1+3} \\
& y-3=\sqrt{3} x-2 \sqrt{3}+8 \text { and } y-3=\sqrt{3} x-2 \sqrt{3}-8 \\
& y=\sqrt{3} x+11-2 \sqrt{3} \text { and } y=\sqrt{3} x-5-2 \sqrt{3}
\end{aligned}
$$

Fig. 3. Solving the problem of equations tangent circle.

In solving the above response the students find the equation of the line and do not proceed because the gradient is known and changing the equation with $\mathrm{c}$ is a constant. The anticipation is to recall the condition of the position of the line that offends a circle based on the discriminant value of the quadratic equation resulting from the equation of the line equation in the circle. The next activity is the formulation by generalizing the problem to determine the equations of the tangent circles so that students more easily understand the procedure so that it can be changed into a general form that is the equation centered at the point $(0,0)$. From the equation that has been formulated into general form then validated by providing tangent equations to the circle, if students can understand how to apply the formula of tangents to certain gradient circles, then the problem solving given can be solved easily and if students are still having difficulties then anticipation given in the form of questions and answers about the equation of the tangent form of the circle.

Here is a picture of a circle tangent equation when the tangent gradient is known (Figure 4). Because the tangent sought must be parallel to the line $y=m x+n$, then it can be assumed that the tangent line is $y=m x+k$. Because the line $y=m x+k$ offends, then there is a point (point of contact) whose coordinates meet the equation of the circle so that it is obtained

$$
\begin{gathered}
x^{2}+(m x+k)^{2}=r^{2} \\
\left(1+m^{2}\right) x^{2}+2 m k x+k^{2}-r^{2}=0
\end{gathered}
$$


This equation is seen as a strong equation. because tangents and circles only have one common point, then the equality equation only has one price $x$, the condition is that the discriminant of the equation must be equal to zero,

$$
\begin{gathered}
D=4 m^{2} k^{2}-4\left(1+m^{2}\right)\left(k^{2}-r^{2}\right)=0 \\
4 m^{2} k^{2}-4 k^{2}+4 r^{2}-4 m^{2} k^{2}+4 m^{2} r^{2}=0 \\
-4 k^{2}+4 r^{2}+4 m^{2} r^{2}=0 \\
-4\left(k^{2}-r^{2}-m^{2} r^{2}\right)=0 \\
k^{2}-r^{2}-m^{2} r^{2}=0 \\
k^{2}=r^{2}+m^{2} r^{2} \\
k= \pm \sqrt{r^{2}+m^{2} r^{2}} \\
k= \pm r \sqrt{1+m^{2}}
\end{gathered}
$$

so, the tangent to the circle $x^{2}+y^{2}=r^{2}$, if the tangent gradient is known, is

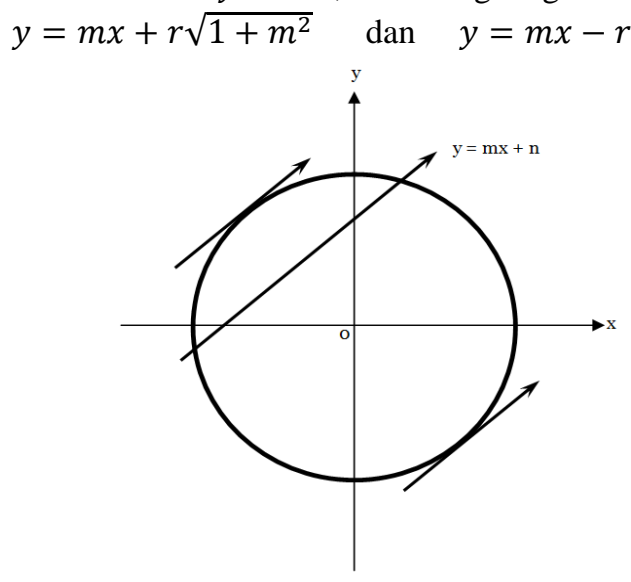

Fig. 4. Tangent circle equation gradient $m$

To help student difficulties, researchers use scaffolding by giving questions and simple instructions on didactic designs. As explained by [5], [7] regarding scaffolding techniques used to direct students' thinking processes in solving problems.

In the apperception section for didactical design, the concept of circle equations and tangent circles aims to find out the prerequisite knowledge students have. According to Brunne, learning that links the prerequisite concepts to the concepts being studied will be effective learning [8]. At the stage of the core activities of the construction process or find understanding and the properties of the circle and tangent circle by giving some exercises questions, while in the closing section is the activity of drawing conclusions related to the concept of circle and tangent circle.

Didactical design that is designed on the equation of a circle and tangent circle can facilitate students in solving problems, although the problem can be solved in groups at least students are able to try to solve the problem given, able to explore the methods used in accordance with the knowledge they have. The didactic design that was developed already considers the learning flow both structurally and functionally, namely the interrelation of concepts and the continuity of student thinking. Most of the stages made in Lesson Design have gone according to predictions. This can be seen from the response of students who are expected to appear in each lesson. 


\section{Conclusion}

In this study the learning obstacle found in the circle equation and tangent circle material is related to the prerequisite material, related to the context of the information obtained and related to problem solving and the concept of the general equation of the circle. The didactic design of the concept of circle equations and tangents of circles is arranged based on the results of the depersonalization of the obstacle found and the student's character is reinforced relevant learning theories.

The development of the concept of circle equations and tangent circles consists of the initial stages of activity, where students' responses in understanding the material and the description of obstacle learning as a result of the implementation of the didactic design. Didactic can be an alternative learning design concept of equation equations and tangents to circles on analytic geometry material.

\section{References}

[1]Suryadi, D.: Ontologi dan Epistemologi dalam Penelitian Desain Didaktis (DDR) .Bandung: Departemen Pendidikan Matematika, UPI (2018)

[2]Suryadi, D.: Metapedidaktik dan Didactical Design Research (DDR): Sintesis Hasil Pemikiran berdasarkan Leson Study, dalam Teori, Paradigma, Prinsip, dan pendekatan pembelajaran MIPA dalam Konteks Indonesia. UPI Bandung (2010)

[3] Moleong, Lexy J.: Metode Penelitian Kualitatif. Bandung: Remaja Rosdakarya (2009)

[4] Suryadi, D.: Didactical Design Research (DDR) to improve the teaching of mathematics. Far East Journal of Mathematics Education, Vol. 10, No. 1, pp. 91-107 (2013)

[5]Vygotsky, L.: Interaction between learning and development. From: Mind and society. Cambridge, MA: Harvard University Press, pp.79-91 (1978)

[6]Brousseau, G.: Epistemological Obstacles, Problems, and Didactical Engineering . Theory of Didactical Situations in Mathematics: Didactique Des MathEmatiques, 1970-1990, pp. 79-117 (2002)

[7] Baharuddin.: Teori Belajar dan Pembelajaran. Jogjakarta. Ar-Ruzz Media (2008)

[8] Suherman.: Belajar da Pembelajaran Matematika. Hands-out Perkuliahan. UPI Bandung (2008) 